\title{
Achados patológicos em pintos de um dia após inoculação experimental com Salmonella pullorum, Salmonella arizonae e Citrobacter diversus
}

\section{Patological findings in one day chicks after experimental inoculation with Salmonella pullorum, Salmonella arizonae and Citrobacter diversus}

\author{
Dayse Lima da Costa Abreu, ${ }^{\star}$ Gicélia Maria da Silva, ${ }^{\star \star}$ Maria Inês Muniz Medeiros, ${ }^{\star \star \star}$

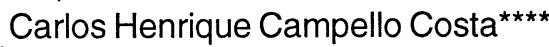

\section{Resumo}

Foram inoculados, experimentalmente, pelas vias oral e saco aéreo, 36 pintos de um dia para que fossem comparados os efeitos patogênicos da Salmonella pullorum, da Salmonella arizonae e do Citrobacter diversus. As lesões foram visualizadas em grupos de pintos mortos naturalmente e/ou sacrificados 10 dias pós-inoculação, e as mais marcantes foram selecionadas para a histopatologia com a coloração de Hematoxilina-Eosina. A maioria das aves inoculadas via oral não apresentou lesões significativas, o mesmo não ocorrendo com as inoculadas via saco aéreo, o que produziu as lesões mais marcantes em todas as aves. As alterações causadas pelas três espécies bacterianas utilizadas foram semelhantes entre si.

Palavras-chave: Enterobacteriaceae; Salmonella; galinhas; Citrobacter.

\section{Introdução}

O uso indiscriminado de terapia antimicrobiana como forma preventiva e/ou curativa contra a salmonelose tem causado variados efeitos e poucos são os dados sobre os benefícios dessa medida. O uso de antimicrobianos pode reduzir ou eliminar salmonelas ou, ainda, aumentar a susceptibilidade à recontaminação (Manning, 1994), mas também exacerbar a população de outras enterobactérias devido aos distúrbios no balanço ecológico da microbiota intestinal (Reynolds et al., 1997).

As Salmonellas, as Shigellas e alguns sorotipos de Escherichia e Arizona são reconhecidamente patogênicas. Entretanto, os gêneros Citrobacter, Proteus, Providencia, Klebsiela, Enterobacter, Serratia e Edwardsiella podem hoje ser responsabilizados como agentes etiológicos de vários processos patológicos (Costa e Hofer, 1972). Dentre esses, destacamos o Citrobacter, que deve ser classificado e identificado com segurança, devido a sua semelhança com outros membros da tribo Salmonellae.

Segundo Nagaraja et al. (1991), os membros do gênero Citrobacternão são conhecidos como sendo patogênicos para aves, mas podem ser confundidos com cultivos de Salmonella.
O presente trabalho tem como objetivo, caracterizar o gênero Citrobactercomo sendo patogênico para aves, assim como as lesões que causam, figurando-o no mesmo nível de importância da Salmonella no que diz respeito à atenção dispensada em termos de diagnóstico, patogenia, controle e profilaxia.

\section{Material e Métodos}

Amostras bacterianas: as amostras de Salmonella pullorum, Salmonella arizonae e Citrobacter diversus foram obtidas do Laboratório de Ornitopatologia da Universidade Federal Fluminense. Essas amostras foram removidas assepticamente de seus meios estoques e com elas foi feito um inóculo com diluição 1:10 (1 $\mathrm{ml}$ de solução bacteriana para $9 \mathrm{ml}$ de água destilada). Essa suspensão produzida foi utilizada para a inoculação das aves.

Aves experimentais: foram obtidos 50 pintos de um dia da linhagem Hubbard, sendo divididos em três grupos de 12 aves, separadas em grupos de seis, conforme o tipo de inoculação feita, se via oral ou via saco aéreo. As 14 aves restantes foram usadas como controle não-inoculado. As gaiolas eram higienizadas diariamente e as aves recebiam água e comida ad libitum.

\footnotetext{
* Mestranda em Ornitopatologia - Faculdade de Veterinária da UFF. Rua Vital Brazil Filho, 64 - C. Postal 100-086, CEP $24230-340$.

**Professora adjunta de Ornitopatologia - Faculdade de Veterinária da UFF. Rua Vital Brazil Filho, 64 - C. Postal 100-086, CEP 24230-340.

*** Pesquisadora. Laboratório de Biologia Animal, PESAGRO/Rio - Alameda São Boa Ventura, 770, Niterói/RJ, CEP $24120-000$.

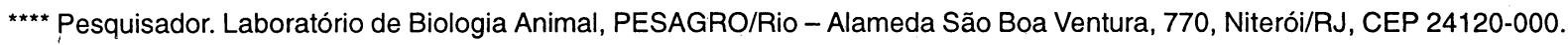


Vias de inoculação: as aves foram inoculadas 24 horas após a eclosão com uma sonda que foi introduzida pela faringe, acoplada a uma seringa esterilizada, contendo 0,5 $\mathrm{ml}$ da suspensão bacteriana. A mesma quantidade foi inoculada via saco aéreo através da introdução de uma aguIha acoplada a uma seringa esterilizada, com o inóculo.

Estudo das lesões: grupos de pintos mortos naturalmente ou sacrificados 10 dias pós-inoculação (PI) foram necropsiados para a visualização das lesões macroscópicas e as mais marcantes foram selecionadas para o estudo histopatológico. A coloração utilizada foi a de Hematoxilina-Eosina.

\section{Resultados}

\section{Achados macroscópicos}

Salmonella pullorum: não havia lesão significativa em 50 $\%(3 / 6)$ das aves inoculadas com Salmonella pullorum pela via digestiva, mas o restante das aves apresentou edema na região abdominal e manchas amareladas no fígado. As lesões de todas as aves inoculadas via saco aéreo com Salmonella pullorum incluem processo inflamatório no local da inoculação, hiperemia de intestino, fígado difusamente amarelado com áreas de necrose no coração e pulmão e uma ave (16,7\%) apresentou nódulos de coloração esbranquiçada na superfície do miocárdio e pulmão.

Salmonella arizonae: apenas uma ave $(16,7 \%)$ inoculada com Salmonella arizonae apresentou o fígado totalmente amarelado em comparação com as outras aves em que o fígado estava com coloração normal. Quando da inoculação com Salmonella arizonae via saco aéreo, todas as aves apresentaram fígado com áreas amareladas ou totalmente amarelado e 33,3\% (2/6) pericardite, pulmão congesto e intestino e proventrículo levemente hemorrágicos.

Citrobacter diversus: Somente $33,3 \%$ das aves (2/6) que foram inoculadas via oral com Citrobacter diversus, apresentaram áreas amareladas no fígado. Das aves inoculadas via saco aéreo com Citrobacter diversus, $100 \%$ apresentaram áreas de inflamação no local da inoculação e fígado com áreas amareladas, e 66,7\% (4/6) mostraram pericardite, focos esbranquiçados no pericárdio e no pulmão - no mesmo lado da inoculação - e intestino congesto.

\section{Achados microscópicos}

Salmonella pullorum: as lesões em $50 \%(3 / 6)$ das aves inoculadas via digestiva com Salmonella pullorum incluem áreas de necrose e degeneração vacuolar no parênquima hepático, áreas de necrose nas criptas do proventrículo e miocardite. Todas as aves inoculadas via saco aéreo com Salmonella pullorum apresentaram infiltração bacteriana acentuada no endocárdio e pericárdio, áreas de necrose no parênquima hepático, degeneração vacuolar e escassa infiltração por células inflamatórias (Figura 1) e áreas de necrose nas vilosidades intestinais.

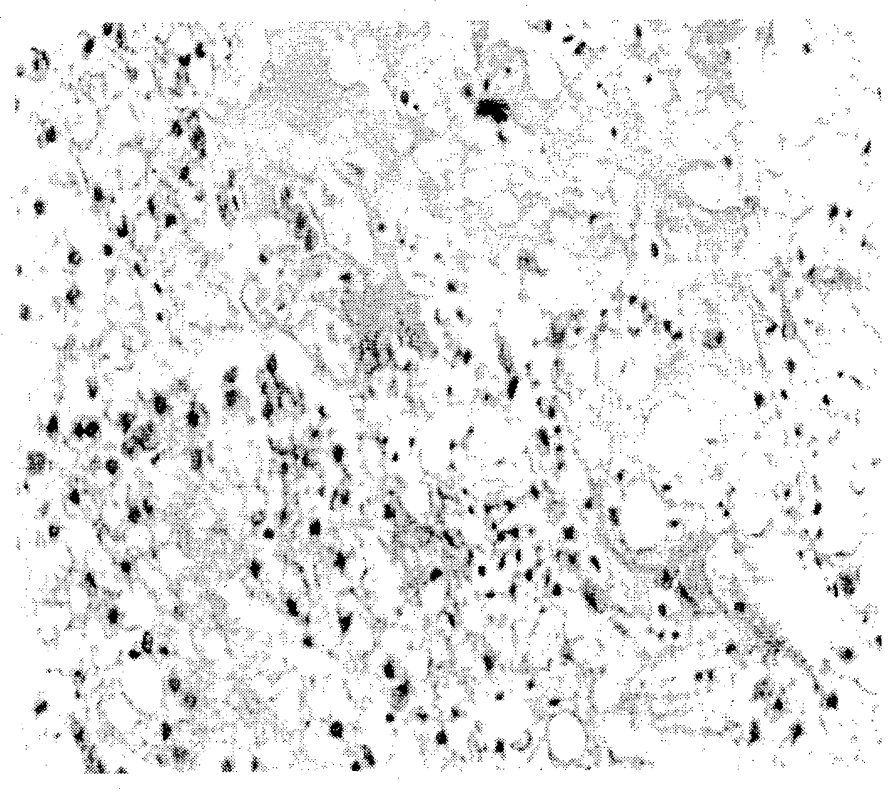

Figura 1: Pinto inoculado com Salmonella pullorum, via saco aéreo. Fígado - Necrose focal no parênquima hepático com escassa reação inflamatória e degeneração vacuolar. (HE, 25 × 065 - MO)

Salmonella arizonae: perihepatite, miocárdio com edema e infiltrado de células mononucleares e acentuada hiperemia pulmonar foram observadas em 16,7\% (1/6) das aves inoculadas via oral com Salmonella arizonae e via saco aéreo, em 100\% ocorreram perihepatite com colonização bacteriana e edema subcapsular (Figura 2). No pulmão se instalou um processo inflamatório catarral, aumento da espessura das paredes alveolares e células descamadas nos brônquios e, no coração, edema (Figura 3), células descamadas e heterófilos (Figura 4).

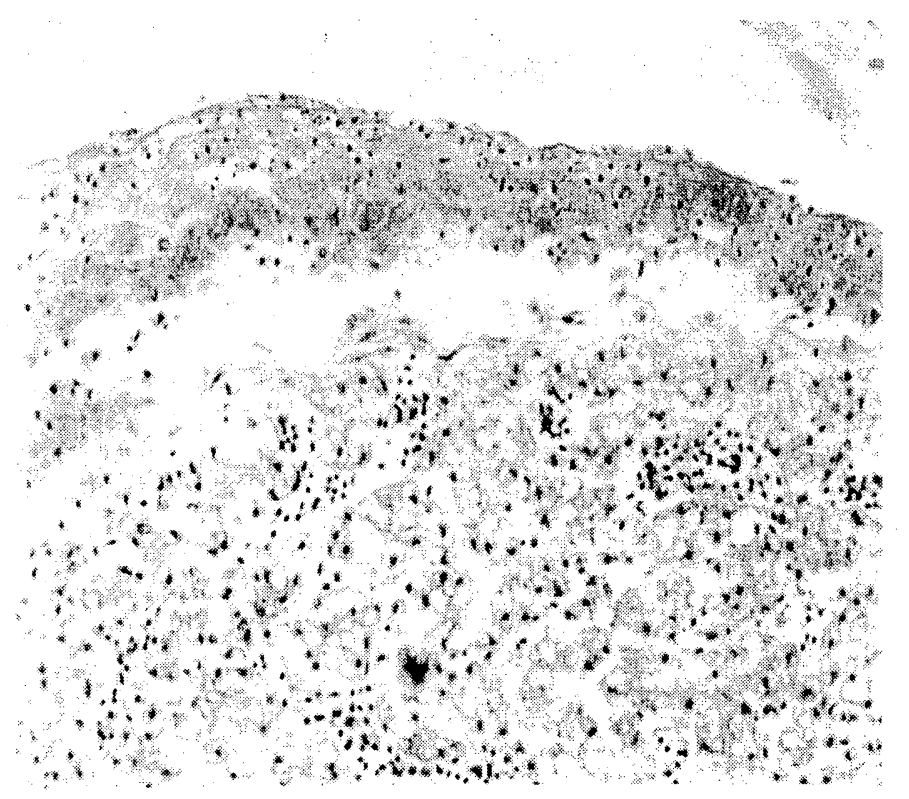

Figura 2: Pinto inoculado com Salmonella arizonae, via saco aéreo. Fígado - Perihepatite. Colonização bacteriana e infiltrado de células inflamatórias na cápsula e colônias bacterianas e edema subcapsular. (HE, $25 \times 065-\mathrm{MO}$ ) 


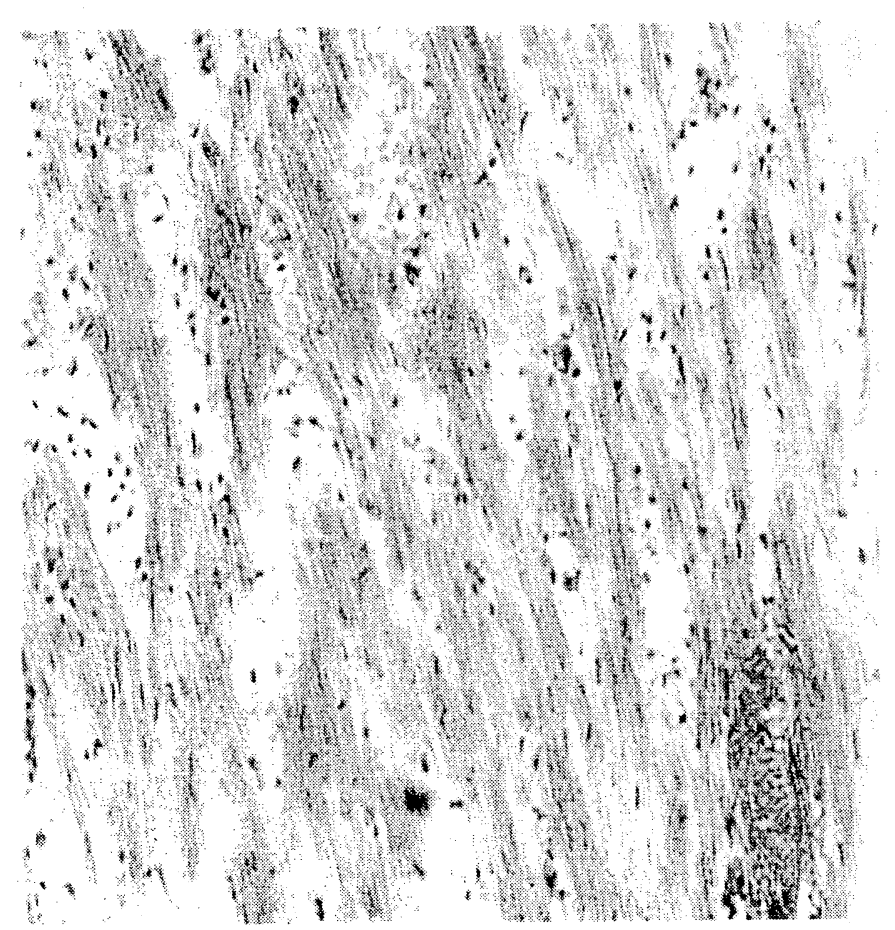

Figura 3: Pinto inoculado com Salmonella arizonae, via saco aéreo. Coração - Edema e presença de colônias bacterianas. (HE, $25 \times$ $075-\mathrm{MO})$

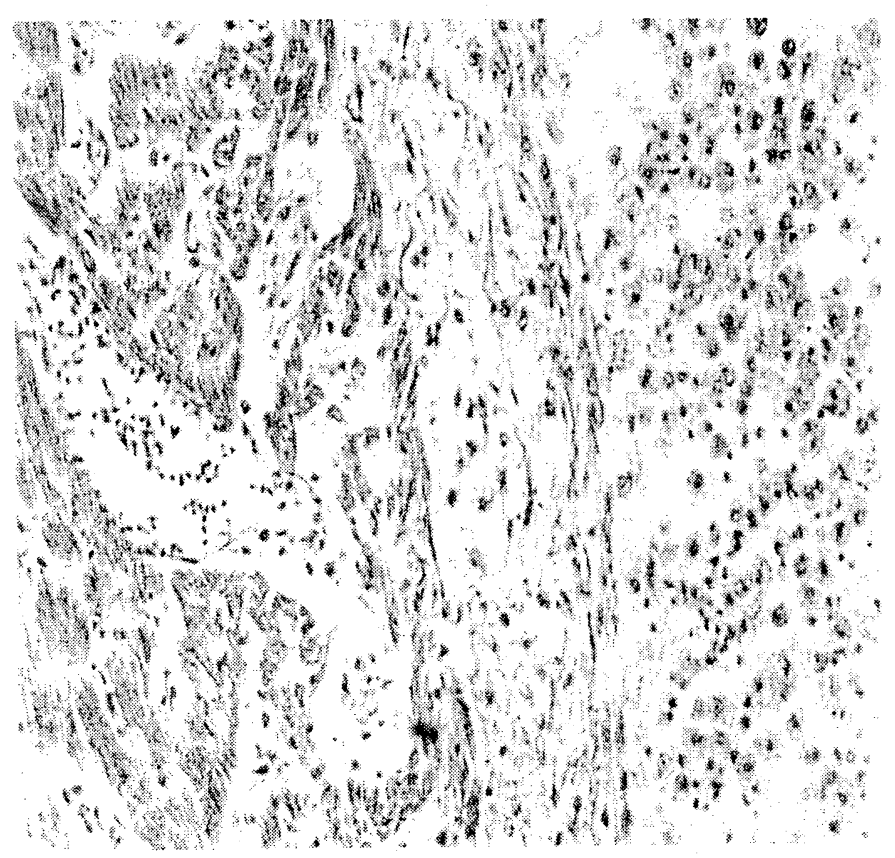

Figura 4: Pinto inoculado com Salmonella arizonae, via saco aéreo. Coração - Pericardite. Extenso infiltrado de heterófilos com células de descamação. (HE, 25 × 075 - MO)

Citobacter diversus: as lesões causadas pela inoculação via oral com Citrobacter diversus se caracterizaram por áreas de hiperemia, necrose e degeneração vacuolar no parênquima hepático de 33,3\% (2/6) das aves. A inoculação via saco aéreo em $100 \%$ das aves produziu, no fígado, degeneração vacuolar, hiperemia e perihepatite. No coração de $66,7 \%$ (4/6) foram observados edema do miocárdio e infiltrado de células mononucleares. O pulmão apresentou broncopneumonia aguda com infiltração heterofílica (Figura 5), o baço, áreas de necrose e infiltrado de células mononucleares e proventrículo com áreas de necrose nas vilosidades das criptas.

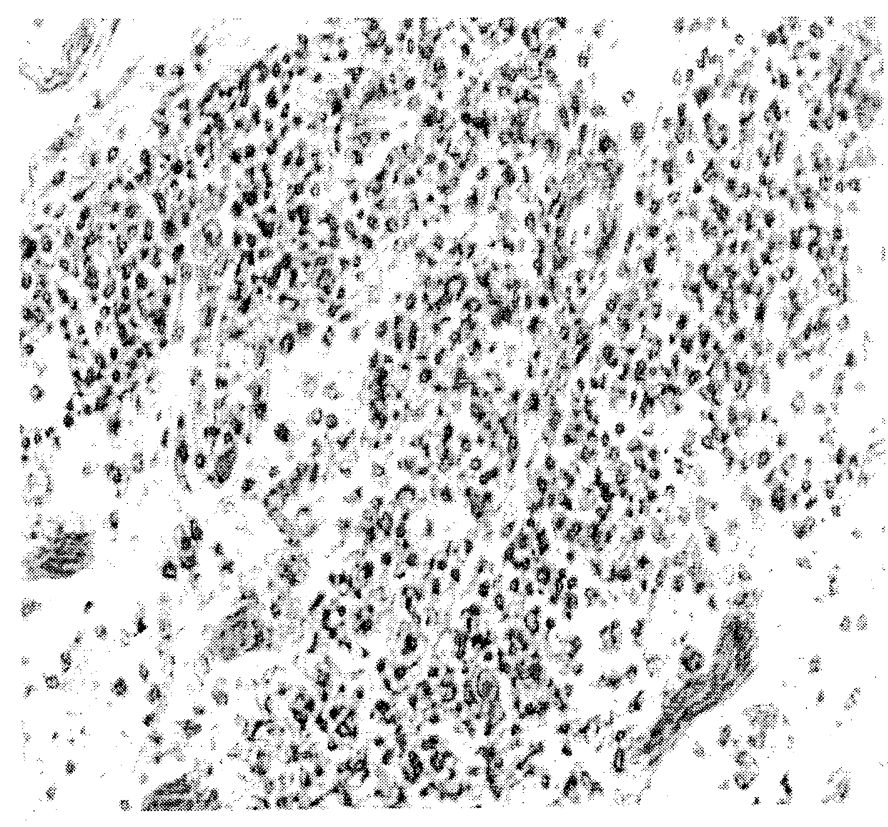

Figura 5: Pinto inoculado com Citrobacter diversus, via saco aéreo Pulmão - Broncopneumonia aguda com infiltração heterofíllica. (HE, $25 \times 075-\mathrm{MO})$

\section{Discussão e conclusões}

Várias lesões foram detectadas após a exposição de pintos de um dia à Salmonella pullorum, Salmonella arizonae e Citrobacter diversus vias oral e saco aéreo, não sendo encontradas em todas as aves, podendo ser devido à susceptibilidade individual.

Nenhuma das aves inoculadas via oral veio a óbito, e a maioria destas desenvolveu lesões insignificantes. As aves inoculadas via saco aéreo apresentaram as lesões mais marcantes e, com isso, podemos reconhecer essa via como a melhor para a reprodução experimental de lesões por bactérias dos gêneros Salmonellae Citrobacter.

Neste estudo, as aves que apresentaram lesões disseminadas em órgãos como coração, pulmão, baço, intestino e proventrículo, foram as que vieram a óbito 24 e 48 horas $\mathrm{PI}-100 \%(6 / 6)$ das aves inoculadas via saco aéreo com Salmonella pullorum e $16,7 \%(1 / 6)$ das inoculadas com Salmonella arizonae via saco aéreo; $66,7 \%(4 / 6)$ das inoculadas via saco aéreo com Citrobacter diversus e 16,7\% $(1 / 6)$ das inoculadas com Salmonella arizonae via saco aéreo, respectivamente - e as que apresentaram lesões 
limitadas, principalmente ao fígado, foram aquelas que não vieram a óbito dentro desse período, sendo sacrificadas 10 dias PI. Esse resultado mostra discordância com os dados relatados por Snoyenbos (1991), que descreve lesões mais limitadas ao fígado em aves que morrem subitamente com pulorose aguda e a forma septicêmica em casos mais prolongados.

Nagaraja et al. (1991) desconhecem o poder patogênico do gênero Citrobacterpara aves, elevando sua importân- cia apenas pelo fato de ele poder ser confundido com a Salmonella em cultivos bacteriológicos por serem semeIhantes bioquimicamente. Neste estudo, o Citrobacterfoi capaz de produzir lesões em aves, sendo estas semeIhantes àquelas causadas pelo gênero Salmonella.

Baseados na observação dos resultados podemos observar que aos três microrganismos deve ser dada a mesma atenção em termos de diagnóstico, patogenia, controle e profilaxia.

\section{Abstract}

Thirty six one day chicks were experimentally inoculated by oral and air sac way to compare the pathologic effects of Salmonella pullorum, salmonella arizonae, and Citrobactyer diversus. The anatomopathologic lesions were showed in naturally dead chick groups and/or in chicks killed 10 days after inoculation, and the best lesions were selected to histopathologic studies with Hematoxilin-Eosin stain. The majority chicks orally inoculated demonstrated no significant anatomohistopathologic lesions and not the same occur with the air sac inoculated chicks that produce the better lesions in all chicks. The lesions caused by the three bacterial species used was very similar between itself.

Keywords: Enterobacteriaceae; Salmonella; chicken; Citrobacter.

\section{Agradecimentos}

Agradecemos à cooperação dos pesquisadores da PESAGRO-Rio por sua ajuda na preparação do material de histopatologia, indispensável para este trabalho e ao CNPq pelo apoio financeiro.

\section{Referências bibliográficas}

COSTA, G.A., HOFER, E. Isolamento e identificação de enterobactérias. Monografia, Instituto Oswaldo Cruz, Rio de Janeiro, 1972. $120 \mathrm{p}$.

MANNING, J. G., HARGIS, B. M., HINTON, A., CORRIER, D. E., DELOACH, J. R., CREGER, C. R. Effect of selected antibiotics and anticoccidials on Salmonella enteritidis cecal colonization and organ invasion in Leghorn chicks. Avian Diseases, v. 38, no. 2, p. 256-261, jul. 1994.

NAGARAJA, K. V., POMEROY, B. S., WILLIAMS, J. E. Paratyphoid Infections. In: CALNEK, B. W. BARNES, H. J., BEARD, C. W.,
REID, W. M., YODER JR, H. W. Diseases of Poultry, $9^{\text {th }}$ ed. Ames, lowa : Ed. lowa State Press, 1991.929 p. Cap. 3, p. 99-130.

REYNOLDS, D. J., DAVIES, R. H., RICHARDS, M., WRAY, C. Evaluation of combined antibiotic and competitive exclusion treatment in broiler breeder flocks infected with Salmonella enterica serovar enteritidis. Avian Pathology, v. 26, no. 1, p. 83-95, 1997.

SNOEYENBOS, G. H. Pullorum Disease. In: CALNEK, B. W., BARNES, H. J., BEARD, C, W., REID, W. M., YODER JR, $H$. W. Diseases of Poultry, $9^{\text {th }}$ ed. Ames, lowa: Ed. lowa State Press, 1991. 929 p. Cap. 3, p. 73-86. 